\title{
Cervical spondylotic radiculo-myelopathy in patients with athetoid-dystonic cerebral palsy: clinical evaluation and surgical treatment
}

\author{
GENJIRO HIROSE, SATORU KADOYA \\ From the Departments of Neurology and Neurosurgery, Kanazawa Medical University, Ishikawa, Japan
}

SUMMARY The acute onset of symptoms of severe cervical radiculo-myelopathy in four patients with athetoid-dystonic cerebral palsy is reported. Neurological and radiological examination showed that the spondylotic changes of the cervical spine were responsible for new neurological deficits leading to the patients being bedridden. Dystonic-athetoid neck movements may cause excessive axial neck rotation as well as flexion and extension movements of the spine. These repetitive exaggerated movements may result in early degenerative changes of the vertebrae which may enhance the radiculo-myelopathy. The four patients were treated with an anterior discectomy with interbody fusion. They were bedridden pre-operatively but all have since been able to walk with or without a cane. It is concluded that early anterior decompression with interbody fusion is a treatment of choice for cervical spondylotic radiculo-myelopathy in association with athetoid cerebral palsy.

Trauma as a cause of cervical spondylosis, with or without neurological deficits, has often been proposed. Reports allude to a causal relationship between movement disorders of the neck and the development of cervical spondylosis, but this relationship has not been clearly established. We have observed the acute onset of cervical radiculomyelopathy in four patients with athetoid-dystonic cerebral palsy. After myelography, all patients were treated surgically.

\section{Case reports}

\section{Case 1}

A 41-year-old woman with athetoid movements since the age of 10 years had undergone a complicated delivery with umbilical cord prolapse, and did not walk alone until the age of 4 years. When aged 40 years she first noted neck and shoulder pain with a numb feeling in the ulnar aspect of the hands. One month later she suddenly developed arm and shoulder pain bilaterally with weakness and tonic spasm of the legs. Since then she had been bedridden. She was referred to us 3 weeks later. She denied urinary or faecal incontinence throughout the course of her illness.

Address for reprint requests: Dr Genjiro Hirose, MD, Department of Neurology, Kanazawa Medical University, Uchinada-machi, Kahoku-gun, Ishikawa Prefecture, Japan, 920-02.

Received 9 September 1983 and in revised form 2 February 1984. Accepted 4 February 1984
Neurological examination revealed generalised athetoid-dystonic movements. No muscle atrophy was noted but she was barely able to extend her arms or to raise her legs from the bed. The right limbs were weaker than the left. She could not stand by herself. There was hypoalgesia in the distribution of C7-C8 bilaterally. Deep tendon reflexes were hyperactive throughout, and bilateral extensor plantar responses were elicited with occasional extensor spasms.

Cervical spine radiographs showed a narrow canal (narrowest antero-posterior diameter, $11.5 \mathrm{~mm}$ at $\mathrm{C} 3-\mathrm{C} 4$ level) and narrowed disc space at the level of $\mathrm{C} 3-\mathrm{C} 4$. Myelography confirmed a disc protrusion with a partial block at the level of C3-C4. She underwent anterior discectomy with the removal of osteophytes, under the operating microscope. No interbody fusion was performed. Athetoid-dystonic movements were controlled with $2.25 \mathrm{~g}$ of levodopa daily. She regained strength in the arms and legs and stood at the 14th postoperative day. Two months after operation her neurological status returned to her previous condition except for sensory impairment.

\section{Case 2}

A 32-year-old man with a history of life-long athetosis and dystonic neck movement secondary to kernicterus had been working as a printer until six months before admission when he noted pain in his shoulders. Three months before admission, he suddenly developed inability to stand or walk due to leg weakness. Despite conservative treatment, his legs and right hand remained weak. He denied urinary or faecal incontinence. 
Neurological examination revealed dystonic and athetoid movements of arms and neck. The interossei were mildly atrophic in the right hand. Muscle strength was diminished bilaterally at deltoid, biceps, triceps to MRC grade $4 / 5$. Wrist extension, flexion and finger abduction were graded as $3 / 5$. He was unable to extend his fingers on the right side. Iliopsoas and quadriceps were graded as $3 / 5$, and gastrocnemei and anterior tibialis muscles were graded as 2/5. In addition to spasticity, he had spontaneous extensor spasms in the legs. Sensory examination revealed mild hypoalgesia and hypoaesthesia over the C5-T1 dermatomes in the right and the C6-T1 dermatomes on the left side. Reflexes were hyperactive throughout, with bilateral extensor plantar responses.

Cervical spine radiographs revealed a canal diameter of $13.5 \mathrm{~mm}$ at $\mathrm{C} 4-\mathrm{C} 5$ level and a reversal of the normal curve in the mid-cervical region, with an exaggerated lordotic curve secondary to a kyphosis beginning at C5 level (fig 1A). The disc space was narrowed at C4-C5 with hypertrophic changes and wedging of the body of C6. Myelography revealed a partial block at the two interspaces, $\mathrm{C} 3-\mathrm{C} 4$, and $\mathrm{C4}-\mathrm{C5}$ with mild compression by the retrolisthesis ventrally and moderate compression dorsally by the folding of the ligamentum flavum occurring in extension (fig 1B, 1C). Anterior discectomy at $\mathrm{C} 3-\mathrm{C} 4$ and $\mathrm{C} 4-\mathrm{C5}$ was performed with anterior interbody fusion. Instability at these two levels was observed during surgery.

Postoperative recovery was slow, and by 6 months hand and arm movements but not sensory loss had improved. By one year, he could stand with support, but marked spasticity in the right leg interfered with ambulation. Two years postoperatively he could walk for a short distance with a cane.
Case 3

A 31-year-old man had athetoid movements since the age of 4 years. He started to walk by himself around 4 years of age. Three months prior to admission, he started to notice numbness of the right 1 st and 2 nd fingers, which gradually progressed up to the elbow over 2 months. One month prior to admission, he suddenly developed weakness in the lower extremities with gait difficulty. One week before admission he was unable to walk by himself. He also complained of difficulty in voiding urine.

Neurological examination revealed a bedridden man with quadriparesis but able to sit up. Dystonic-athetoid movements were noted around the neck and shoulders. Sternocleidomastoid muscles were hypertrophic. There was severe atrophy of the shoulder girdle bilaterally. Marked atrophy and weakness of the deltoid, biceps, triceps brachii and moderate atrophy and weakness of the forearm extensors as well as flexors, were also noted. There was mild bilateral atrophy of the dorsal interossei. The legs showed no atrophy but hip flexors, hamstrings and anterior tibial compartments were weak in the range of $4 / 5$, whereas gluteal power was intact. Sensory examination revealed hypoaesthesia to pin prick involving both sides of the lateral aspect of the upper arm, forearm and hand. Vibration sense was severely impaired below the iliac crest. Position sense was almost abolished in the arms and legs. Biceps, triceps and brachioradialis jerks were absent with inversion of biceps and brachioradial reflexes. Finger jerks were hyperactive as well as knee and ankle jerks bilaterally. Plantar responses were extensor and he had Lhermitte's sign.

Cervical spine radiographs revealed a constitutionally narrow canal (12 mm at C3-C4 level) (fig 2A). Tomogra-

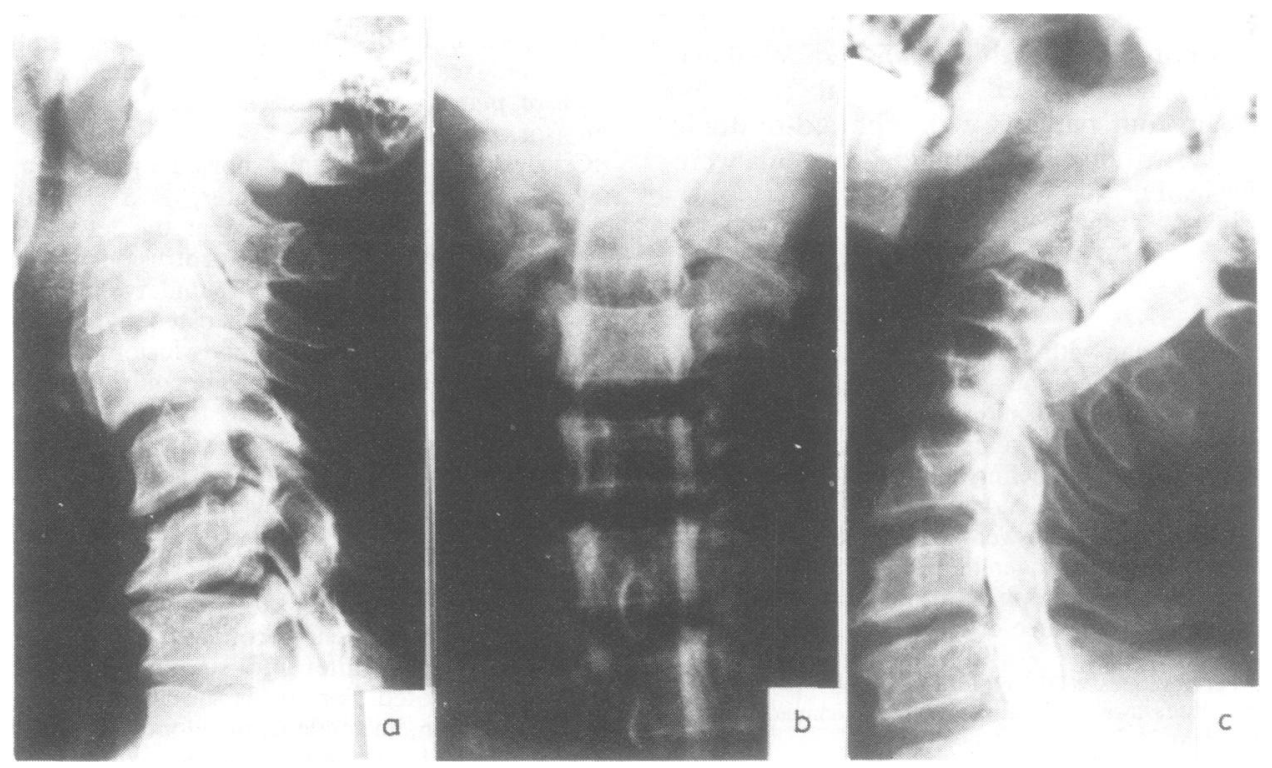

Fig 1 Radiographs of Case 2. (A) Lateral view in neutral position, (B) Postero-anterior view of myelography, (C) Lateral view of myelography in extension. 


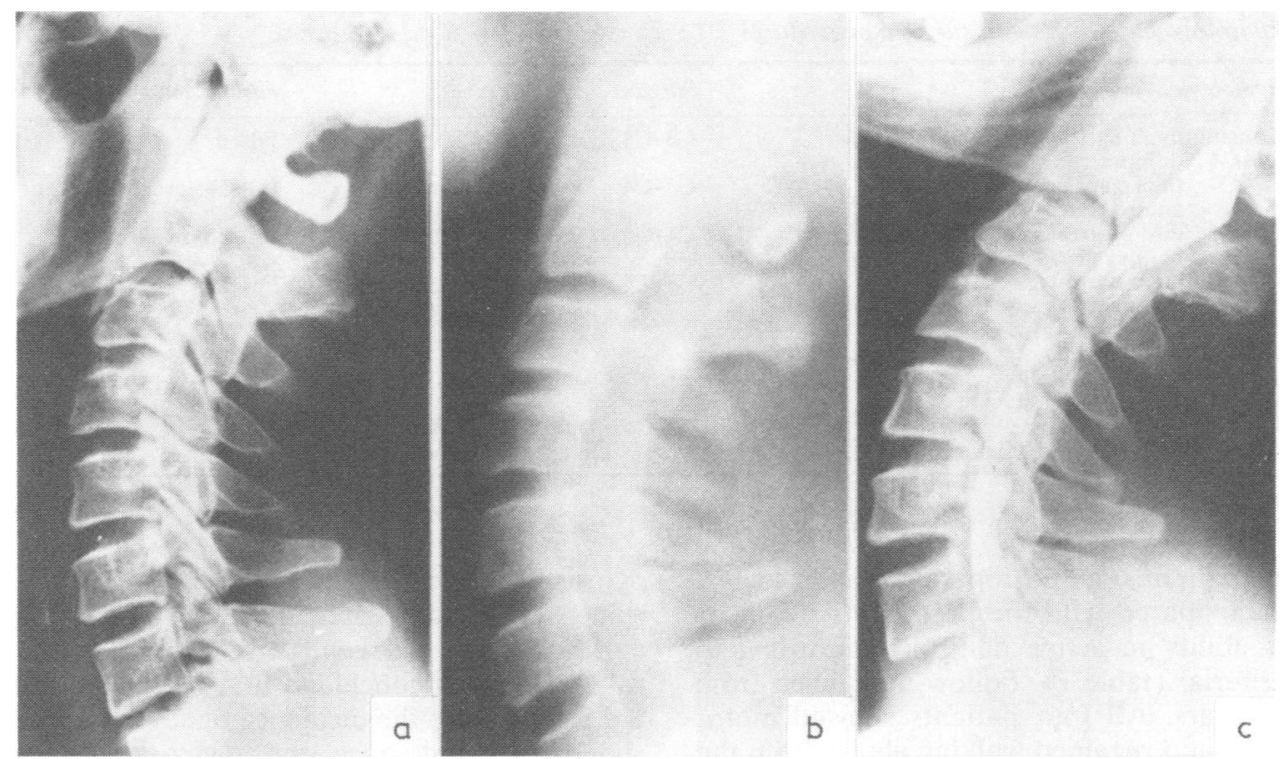

Fig 2 Radiographs of Case 3. (A) Lateral view in neutral position, (B) Lateral tomogram of the spine,

(C) Lateral view of myelography in extension.

phy of the cervical spine showed mild spondylotic changes and retrolisthesis at $\mathrm{C} 3-\mathrm{C} 4$ disc space (fig 2B). Myelography revealed a subtotal block at the level of $\mathrm{C} 3-\mathrm{C} 4$ with a soft disc and retrolisthesis of the $\mathrm{C} 3$ vertebral body. Dorsal indentation by the thickened ligamentum flavum in extension posture at $\mathrm{C} 3-\mathrm{C} 4, \mathrm{C} 4-\mathrm{C} 5, \mathrm{C} 5-\mathrm{C} 6$ and $\mathrm{C} 6-\mathrm{C} 7$ was noted (fig 2C).

Because of slow progression of his quadriparesis and mild bladder dysfunction over a week, he underwent surgery with C3-C4 anterior discectomy and interbody fusion. A midline osteophyte with a degenerated disc protrusion and thickened posterior longitudinal ligament were found at $\mathrm{C} 3-\mathrm{C} 4$ level. Postoperatively urinary incontinence subsided within 2 months and he could walk without assistance by one year, but atrophy was unchanged in the shoulder girdle as well as in the left arm. Leg strength improved significantly to only minimal weakness.

\section{Case 4}

A 27-year-old man delivered at full term had athetoid movements from the age of 6 months. His early developmental milestones were delayed and he started to walk around 2 years of age. He had a mild motor handicap but was able to do school gymnastics. Four years before admission, he complained of right leg weakness and numbness in both hands. Two years before admission, he suddenly experienced weakness of both legs which lasted only for 2 days. One month prior to admission, he developed weakness of his left arm and was referred to us. He denied bladder and bowel problems.

Neurological examination revealed dystonic neck movements with a hypertrophic left sternocleidomastoid muscle. There was severe muscle atrophy over the left C5-C6 distribution with fasciculation. Power in biceps was $4 / 5$ on the right and $3 / 5$ on the left, triceps right $4 / 5$ and left
3/5. Brachioradialis and wrist extension and flexion were also weak. Left interossei were weak and atrophic. In the legs, quadriceps and iliopsoas were weak (4/5). Gastrocnemei were $3 / 5$ and anterior tibial muscles were $4 / 5$. He could not walk alone. There was decreased sensation to pin-prick and light touch below T5. Tendon reflexes were decreased in biceps and increased in the legs with bilateral extensor plantar responses. Cervical spine radiographs revealed a spinal canal measuring $13 \mathrm{~mm}$ at the level of $\mathrm{C} 3$, and marked degenerative bone changes at the level of C3-C4. Flexion and extension neck movements showed retrolisthesis at this level. Myelography revealed a partial block at $\mathrm{C} 3-\mathrm{C} 4$ caused by marked osteophytes and retrolisthesis. Compression by a thickened ligamentum flavum posteriorly was also apparent. An anterior discectomy with interbody fusion was done at $\mathrm{C} 3-\mathrm{C} 4$ level; marked osteophytes were also found at the time of operation.

Postoperatively he could walk using a frame. Arm function improved in a month. Five months postoperatively he could walk slowly using a cane.

\section{Results of surgical treatments}

Anterior operation was carried out in these four patients and all tissues compressing the cervical cord and roots were removed under an operating microscope. Interbody fusions were performed in all patients except for the Case 1 (table 1). Consequently four interspaces (C3-C4: 3, C4-C5: 1) were fused by autogenous iliac bone grafts and one interspace $(\mathrm{C} 3-\mathrm{C} 4)$ was operated without a bone graft implantation. A single level operation was performed in three patients and two levels were oper- 
Table 1 Radiological findings and surgical procedures

\begin{tabular}{|c|c|c|c|c|}
\hline \multirow{2}{*}{$\frac{\text { Case }}{1}$} & \multirow{2}{*}{ Radiological findings } & \multicolumn{2}{|c|}{ Surgical procedures } & \multirow{2}{*}{$\begin{array}{l}\text { Fusion status } \\
\text { Fused }\end{array}$} \\
\hline & & $\mathrm{C} 3-\mathrm{C} 4$ & Discectomy* & \\
\hline 2 & $\begin{array}{l}\text { C3-C4 thickened lig. flavum } \\
\text { antero-/retro-listhesis }\end{array}$ & $\mathrm{C} 3-\mathrm{C} 4$ & Discectomy with & C3-C4: pseudoarthrosis \\
\hline & $\begin{array}{l}\text { C4-C5 disc protrusion and thickened } \\
\text { lig. flavum antero-retro-listhesis }\end{array}$ & $\mathrm{C} 4-\mathrm{C} 5$ & $\begin{array}{l}\text { Discectomy with } \\
\text { interbody fusion }\end{array}$ & C4-C5: fused \\
\hline 3 & $\begin{array}{l}\text { Constitutional narrow canal } \\
\text { C3-C4 disc protrusion with thickened } \\
\text { lig. flavum retrolisthesis }\end{array}$ & $\mathrm{C} 3-\mathrm{C} 4$ & $\begin{array}{l}\text { Discectomy with } \\
\text { interbody fusion }\end{array}$ & Fused \\
\hline & $\begin{array}{l}\text { C4-C5 thickened lig. flavum } \\
\text { C5-C6 } \\
\text { C6-C7 } \\
\text { thickened lig. flavum } \\
\text { thiced lig. flavum }\end{array}$ & & & \\
\hline 4 & $\begin{array}{l}\text { spondylotic osteophytes } \\
\text { thickened lig. flavum retrolisthesis }\end{array}$ & $\mathrm{C} 3-\mathrm{C} 4$ & $\begin{array}{l}\text { Discectomy with } \\
\text { interbody fusion }\end{array}$ & Fused \\
\hline
\end{tabular}

*No bone graft implanted.

lig. flavum = ligamentum flavum.

ated in one patient. The postoperative neurological status was compared with the preoperative deficits as well as ability in active daily life according to Odom's criteria' (table 2). Follow-up ranged from 1.4 to 4.5 years. All four patients showed motor improvement and regained walking ability from the preoperative bedridden state. Sensory status and reflexes remained unchanged. Urinary incontinence in one patient (Case 3 ) recovered soon after surgery. All four patients showed some recovery of their limited physical activities in active daily life during postoperative follow-up, and these were judged as fair according to Odom's criteria.'

\section{Discussion}

Few reports ${ }^{2-4}$ mention the relationship between cervical spondylosis and dyskinesia. Freiman et $a^{2}$ first reported dystonic amyotrophy but did not mention the changes in the cervical spine. Anderson et $a l^{3}$ reported congenital athetosis with cervical spon- dylosis in two patients. They also examined cervical spine films of nine patients with athetosis. Two of nine patients had degenerative changes in the cervical spine. They concluded that prolonged athetosis did not increase the incidence or severity of cervical spondylosis but once the degenerative changes occurred, this might initiate or aggravate the associated myelopathy. Levine $e t a l^{4}$ in a study of 20 patients with movement disorders suggested that severe dyskinesia can be responsible for spondylosis and resulting neurological deficit. They found moderate to marked spondylotic changes of the spine in $50 \%$ of the patients.

Yamashita et $a l^{5}$ reported 10 cases of cervical spondylotic radiculo-myelopathy caused by dystonic cerebral palsy. They also reported a greater frequency of spondylotic changes at $\mathrm{C} 3$ and $\mathrm{C} 4$ in this disorder as compared with the changes in cervical spondylosis without dyskinesia, and stressed the early onset of cervical spondylosis in those patients.

We have reviewed 251 cases of cervical spon-

Table 2 Preoperative and postoperative neurological status and follow up periods

\begin{tabular}{|c|c|c|c|c|c|c|c|}
\hline Case & Motor functions & Ambulatory status & Sensory status & Refiexes & Bladder & $\begin{array}{l}\text { Follow up } \\
\text { periods }\end{array}$ & $\begin{array}{l}\text { Odom's } \\
\text { criteria }\end{array}$ \\
\hline 1 & $\begin{array}{l}\text { Upper limbs } \\
\rightarrow \text { improved } \\
\text { Lower limbs } \\
\rightarrow \text { improved }\end{array}$ & $\begin{array}{l}\text { Bedridden } \\
\rightarrow \text { able to walk }\end{array}$ & $\stackrel{\text { Deficits }}{\rightarrow \text { Unchanged }}$ & Unchanged & $\mathbf{N} \rightarrow \mathbf{N}$ & 4.5 years & Fair \\
\hline 2 & $\begin{array}{l}\text { Upper limbs } \\
\rightarrow \text { improved } \\
\text { Lower limbs } \\
\rightarrow \text { improved }\end{array}$ & $\begin{array}{l}\text { Bedridden } \\
\rightarrow \text { walk several } \\
\text { steps with a } \\
\text { cane }\end{array}$ & $\stackrel{\text { Deficits }}{\rightarrow}$ Unchanged & $\begin{array}{l}\text { Unchanged } \\
\text { except for } \\
\text { right leg } \\
\text { worse }\end{array}$ & $\mathbf{N} \rightarrow \mathbf{N}$ & $1 \cdot 4$ & Fair \\
\hline 3 & $\begin{array}{l}\text { Upper limbs } \\
\rightarrow \text { unchanged } \\
\text { Lower limbs } \\
\rightarrow \text { improved }\end{array}$ & $\begin{array}{l}\text { Bedridden } \\
\rightarrow \text { able to walk }\end{array}$ & $\begin{array}{l}\text { Deficits } \\
\quad \rightarrow \text { Unchanged }\end{array}$ & Unchanged & $A \rightarrow \mathbf{N}$ & $2 \cdot 5$ & Fair \\
\hline 4 & $\begin{array}{l}\text { Upper limbs } \\
\rightarrow \text { improved } \\
\text { Lower limbs } \\
\rightarrow \text { improved }\end{array}$ & $\begin{array}{l}\text { Bedridden } \\
\rightarrow \text { walk with a } \\
\text { cane }\end{array}$ & $\begin{array}{l}\text { Deficits (?) } \\
\quad \rightarrow \quad \text { Improved }\end{array}$ & Unchanged & $\mathbf{N} \rightarrow \mathbf{N}$ & $2 \cdot 1$ & Fair \\
\hline
\end{tabular}

$\mathrm{N}$ : Normal $=$ no urinary incontinence.

A: Abnormal = urinary incontinence. 
dylosis seen over five years in our clinic, of whom only four had cervical spondylotic radiculomyelopathy in relation to dystonic-athetoid movement. The mean age at onset of spondylotic symptoms in these four patients was 33 years and this coincides with results of others, ${ }^{45}$ who reported the early onset of spondylosis in patients with dystonia. In 43 surgically treated patients with non-dystonic cervical spondylotic myelopathy, the average age was 55 years at the time of operation; only two were less than 40 years old, and both had combined lesions such as a constitutionally narrow canal and a congenital fusion of $\mathrm{C} 2$ and $\mathrm{C} 3$. We assume that involuntary neck movement due to cerebral palsy was a contributing factor to the early onset of spondylotic radiculo-myelopathy in our cerebral palsy patients in whom degenerative spondylotic changes occurred mostly at the C3-C4 level. The C4-C5 and C5-C6 disc spaces, generally regarded as the common sites of cervical spondylotic changes, were much less affected in these subjects. According to $\mathrm{O}^{\prime}$ Connell, ${ }^{6}$ the capacity for flexion and extension of the normal spinal column is maximal at the 5th and 6th cervical vertebrae, which might explain the frequent degenerative changes seen at C5-C6. But rotatory movement seen in cervical dystonia or torticollis may be different because the uppermost cervical vertebra produce most of the rotation of the neck and the lower cervical vertebrae produce most of the flexion and extension. Thus 40 to $50 \%$ of axial neck rotation occurs at upper cervical spines $(\mathrm{C} 1-\mathrm{C} 2)$ and the remainder occurs at the joints s. $^{\circ}$ lower cervical spines.' This might explain the greater degenerative changes of the upper spine in torticollis patients.

Dystonia and athetosis could result in early degenerative changes of the vertebrae. The chronic and violent involuntary movements of dystonic and athetoid type might thus contribute to the production of cervical spondylosis and resulting neurological deficits. Once spondylosis is present, dyskinesia may enhance myelopathy and radiculopathy because of the combination of factors.

In our small series, two out of four patients had a constitutionally narrow spinal canal, and three had a thickened, folded ligamentum flavum, shown by myelography in neck extension. Both the constitutionally narrow canal ${ }^{8}$ and the thickened ligamentum flavum ${ }^{9}$ have been considered important factors in the development of radiculo-myelopathy in cervical spondylosis. It is obvious that a degenerated ligamentum flavum compresses the cervical cord either continuously or intermittently during neck movements and leads to myelopathy. ${ }^{9}$ Spinal instability is also an important factor for understanding the pathogenesis of spondylotic radiculo- myelopathy. The pinching effect of retrolisthesis on the cervical cord has to be emphasised. This kind of instability, antero- and retro-listhesis, was present in three patients (C3-C4: 3, C4-C5: 1). Although the incidence of cervical spondylotic radiculomyelopathy itself is not necessarily high in patients with dystonic involuntary movements, a cause and effect relationship in individual cases between the dystonic neck movements and subsequent development of cervical spondylosis with radiculomyelopathy appears incontrovertible. The long duration of abnormal involuntary movements may accelerate the degenerative processes in the spine, discs and ligaments. ${ }^{10}$ If there are preexisting congenital defects of the spine such as a narrow canal, the movement disorder may also produce cord damage.

There are few reports of the results of therapy in such patients. Levine ${ }^{4}$ reported a patient who had an extensive laminectomy from $\mathrm{C} 2$ to $\mathrm{T} 1$ without improvement. Surgical treatment for cervical spondylotic myelopathy has yielded a wide range of results. Advocates of different surgical procedures have claimed variable results following operation for cervical spondylotic radiculo-myelopathy. In general, operations for cervical spondylotic radiculopathy have produced better results than those procedures for myelopathy. Improvement in disability following anterior interbody fusion and a tendency for disability to worsen following all varieties of laminectomy were suggested by Gregorius et $a l^{11}$ in their long-term follow up study.

The radiological findings (table 1) suggest that both anterior and posterior components were contributing to the spondylotic radiculo-myelopathy of our four patients. Multiple laminectomies in the adult cervical spine may lead to clinical instability with serious neurologic consequences. Patients with abnormalities of the spine such as disc degeneration or antero- or retro-listhesis, are prone to develop instability after laminectomy. Three out of our four patients had antero- or retro-listhesis in flexion or extension movement prior to surgery (table 1). In addition all patients had a long history of dystonic neck movements, which themselves may cause cervical instability. We preferred an anterior discectomy and osteophytectomy to a laminectomy, since the former could eliminate the anteriorly located compressive components such as protruded discs and osteophytes and prevent cervical instability by interbody fusion. The presence of a constitutionally narrow canal generally favours the choice of laminectomy, but in our patients with athetosis and dystonia, we feared that laminectomy might worsen cervical instability.

Our microsurgical anterior operation resulted in 
clinical improvement of myelopathy even though a narrow canal was also present. ${ }^{1213}$ Postoperatively, all patients wore a neck collar constantly for one month and were advised to wear it by day for at least a further month. We have followed them for up to four and a half years and their condition has been stable without deterioration. Despite continuing neck movements, postoperatively, the result of the fusion state during this period revealed a good body fusion in four out of five level operations, and a pseudoarthrosis in one patient who had interbody fusion at two levels (table 1).

We conclude that early decompression by an anterior discectomy with interbody fusion is beneficial for patients with cervical spondylotic radiculomyelopathy secondary to athetoid-dystonic involuntary movements.

\section{References}

' Odom GL, Finney W, Woodhall B. Cervical disk lesion. JAMA 1958;166:23-8.

${ }^{2}$ Freiman IS, Luwisch J. Dystonic amyotrophy, dystonia and muscular atrophy. Neurology (Minneap) 1956;6:108-14.

${ }^{3}$ Anderson WW, Wise BL, Itabashi JJ, Jones M. Cervical spondylosis in patients with athetosis. Neurology (Minneap) 1962;12:410-12.

${ }^{4}$ Levine RA, Rosenbaum AE, Waltz JM, Scheinberg LC.
Cervical spondylosis and dyskinesia. Neurology (Minneap) 1970;20:1194-9.

s Yamashita Y, Kuroiwa Y. Cervical radiculomyelopathy caused by cerebral palsy (dystonic type)-Clinical evaluation of our 10 cases-Saishin Igaku (Japanese) 1979;34:293-7.

- O'Connell JEA. Cervical spondylosis. Proc $R$ Soc Med 1956;49:202-8.

7 White AA, Panjabi MM. Clinical Biomechanics of the Spine. JB Lippincott Comp., 1978: 61-90.

${ }^{8}$ Paine EE, Spillane JD. The cervical spine. An anatomico-pathological study of 70 specimens (using a special technique) with particular reference to the problem of cervical spondylosis. Brain 1957;80:57196.

9 Stoltmann, HG, Blackwood W. The role of the ligamenta flava in the pathogenesis of myelopathy in a cervical spondylosis. Brain 1964;87:45-50.

${ }^{10}$ Reid JD. Effect of flexion-extension movements of the head and spine upon the spinal cord and nerve roots. $J$ Neurol Neurosurg Psychiatry 1960;23:214-22.

" Gregorius FK, Estrin T. Crandall PH. Cervical spondylotic radiculopathy and myelopathy. A long-term follow-up study. Arch Neurol 1976;33:618-25.

${ }^{12}$ Kadoya S, Nakamura T, Hirose G, Yamamoto T. Microsurgical anterior approach for cervical spondylotic radiculomyelopathy. Neurol Med Chir (Tokyo) 1980;20:273-80 (Japanese).

${ }^{13}$ Kadoya S, Kwak R, Hirose G, Yamamoto T. Cervical spondylotic myelopathy treated by a microsurgical anterior approach with or without interbody fusion. In: Brock M, ed. Modern Neurosurgery, 1st ed. Berlin: Springer-Verlag, 1982: 292-8. 